\title{
Factors associated with adverse events after emergency laparotomy in Cape Town, South Africa: Identifying opportunities for quality improvement
}

\author{
Richard Trafford Spence ${ }^{1,2 *}$, Mark Hampton ${ }^{3}$, Kent Pluke ${ }^{2}$, Mariam Kahn $^{2}$, Nkhabe Chinyepi ${ }^{2}$, Mohamed Elmusbahi ${ }^{2}$, Tirsa van Wyngaard ${ }^{2}$ \\ and Eugenio Panieri \\ ${ }^{1}$ Codman Center Massachusetts General Hospital, USA \\ ${ }^{2}$ University of Cape Town, Groote Schuur Hospital, South Africa \\ ${ }^{3}$ Victoria Hospital, Department of General Surgery, USA
}

\begin{abstract}
Background: Surgical outcomes research is limited in areas of the world with the greatest unmet surgical need and likely greatest variation in outcomes. Measurement alone may improve outcomes - the so-called Hawthorne effect. The purpose of this multi-center cohort study was to identify factors that are both feasible to collect and are associated with a major adverse event following a targeted procedure in Cape Town, South Africa.

Methods: A collaborative of four acute care surgical units was formed to develop a dataset with minimal data burden describing outcomes following an emergency exploratory laparotomy during a 3-month period (February-April 2015). Controlling for patient, problem, provider, procedure and process predictors, multivariate models were built to identify risk factors for a major adverse event and higher resource use following surgery in our collaborative.

Results: The outcomes of 450 exploratory laparotomies from the four participating hospitals were audited, 319 (70.9\%) were for non-trauma and 131 (29.1\%) were for trauma. The major adverse event rate was $15.7 \%$ (95\% CI $12.6-19.4)$. In the multivariate analysis, factors associated with the primary outcome included age, American Society of Anesthesia score of greater than 2, bowel resection, pre-operative CT scan and a non-therapeutic laparotomy. A major adverse event was associated with all three outcomes assessing increased resource utilisation.

Conclusion: This study supports the comparative outcome assessment of a high volume or high risk procedure as a proxy for measuring the quality of care provided in a surgical collaborative. Such an exercise can identify opportunities for quality improvement.
\end{abstract}

\section{Introduction}

Measuring the quality of medical care has become extremely important to patients, payers, and providers in the past few decades [1]. The framework defined by Avedis Donabedian to measure quality of medical care involves three concepts -structure, process, and outcomes [2]. In surgery, outcomes have been the most widely used indicator, as they are the easiest to measure and understand. In addition, measurement alone may improve outcomes-the so-called Hawthorne effect $[1,3]$. The main limitation of the use of outcome indicators, however, is the need for risk-adjustment [4,5]. In other words, the pre-surgical severity of illness and the procedure performed must be accounted for if outcome indicators are to be used in the comparative assessment of the quality of surgical care.

In United States, the American College of Surgeons National Surgical Quality Improvement Program (ACS-NSQIP) is the most robust risk-adjusted and reliable tool available [5]. The ACS-NSQIP has been shown to reduce both morbidity and mortality in enrolled hospitals with initially worse performing hospitals having the greatest likelihood of improvement [6,7]. Following the success of the ACS-NSQIP, the American College of Surgeons Trauma Quality Improvement Program (ACS-TQIP) was developed. A significant limitation with these programs is they require retrospective collection of over 130 variables. For low to middle income countries (LMIC) with limited resources, extrapolating this type of quality measure would be challenging. Research has shown as few as six data variables may be all that is needed for adequate risk-adjustment [8]. However, indicators that would accurately reflect the quality of care and be the best outcome predictors of these measures in a LMIC are unknown.

Auditing the outcomes of all operations at a hospital is difficult. Choosing one or two operations as proxies for the quality of all surgical care provided has been recently proposed [1]. We chose to study Emergency Laparotomy, (EL) recently declared by the The Lancet Commission on Global Surgery to be a, 'Bellwether procedure', or one that all district hospitals should be able to provide safely [9]. Specifically, we aimed to identify factors that are both feasible to collect and are associated with a major adverse event after emergency laparotomy in Cape Town, South Africa. We hypothesized that a major adverse event was further associated with increased resource utilisation.

Correspondence to: Richard Trafford Spence, Codman Center for Clinical Effectiveness in Surgery, Charles River Plaza, Suite 1403, 165 Cambridge Street, Boston, MA 02114, USA, Tel: +27 613001212, Fax: +2721 8801114; E-mail: rtspence@mgh.harvard.edu

Received: February 04, 2016; Accepted: March 17, 2016; Published: March 21 , 2016 


\section{Material and methods}

\section{Study sites}

The health district of the greater Cape Town area is known as the Cape Metro West Health District and serves an estimated population of 2, 292000 [10]. Four government hospitals; two district level hospitals (Mitchell's Plain District Hospital [MPH] and Victoria War Memorial Hospital [VWH]), one regional level hospital (New Somerset Hospital [NSH]) and one central referral hospital (Groote Schuur Hospital [GSH]) were included in this study.

\section{Patient population}

Consecutive patients older than 12 years undergoing EL at one of the four hospitals during the study period (1st February 2015- 30th April 2015) were included. EL was defined as any abdominal operation requiring open or laparoscopic exploration for emergency (unplanned) indications, trauma or otherwise.

\section{Method of data capture}

REDCap (Research Electronic Data Capture), a free, secure, webbased application was used for its ease to capture real time data [11]. A formal introduction to the study was made to all general surgeons and trainees at the participating hospitals and two clinicians per hospital were responsible for the data capture. Data was entered using mobile phones or electronic tablets during ward rounds. Hospital theatre registries were reviewed daily at each site to ensure no eligible cases were missed.

\section{Variables for inclusion}

After reviewing the variables required in the ACS-NSQIP and TQIP programs, variables used in another study reporting international outcomes after abdominal surgery [12], and adding contextually relevant variables for South Africa such as HIV status and highest qualification of attending clinicians, 32 pre and intraoperative variables were chosen. These are presented under patient, problem, provider, procedure and process subheadings in Table 1.

\section{Outcomes}

The primary outcome was major postoperative Adverse Event (AE) defined by the Clavien-Dindo classification system as grade three or higher (Table 2). This included any AE requiring surgical, endoscopic or radiological intervention or resulting in death. Secondary outcome used as proxies for resource utilization inclabuded [13].

- Length of stay of greater than 30 days (LOS $>30$ )

- Post operative ICU admission

- Unplanned reoperation.

Table 1. Perioperative data variables for risk- adjusted benchmarking of emergency abdominal surgery.

\begin{tabular}{|c|c|c|}
\hline Variable & Data type & Categories \\
\hline \multicolumn{3}{|l|}{ Patient variable } \\
\hline Unique study identifier & Continuous & \\
\hline Age & Continuous & \\
\hline Race & Categorical & Black, White, Asian, Indian, Mixed ancestry \\
\hline Sex & Binary & Male, female \\
\hline ASA Classification & Ordinal & Graded 1-5 \\
\hline Charlson comorbidity index & Ordinal & Graded 1-6 \\
\hline Functional health status & Categorical & Independent, partially dependent, dependent \\
\hline HIV Status & Categorical & HIV positive, HIV negative, HIV status unknown \\
\hline CD 4 count & Continuous & \\
\hline Diabetic status & Categorical & Insulin dependent, non-insulin dependent, not diabetic \\
\hline Current smoker & Binary & Yes, No \\
\hline BMI & Categorical & Underweight, normal, overweight, obese \\
\hline GCS on arrival & Ordinal & Graded $3-15$ \\
\hline Blood pressure on arrival & Continuous & \\
\hline $\begin{array}{l}\text { Airway compromised on arrival } \\
\text { or transfer requiring intubation }\end{array}$ & Binary & Yes, No \\
\hline \multicolumn{3}{|l|}{ Problem variable } \\
\hline Diagnosis & Categorical & Dropdown of 36 options provided \\
\hline Mechanism of injury & Binary & Firearm, knife, blunt, not applicable \\
\hline \multicolumn{3}{|l|}{ Provider variable } \\
\hline Hospital & Categorical & Hospital 1-4 \\
\hline Qualification of surgeon & Categorical & $\begin{array}{l}\text { Sub-specialist, Fellow, Consultant, Registrar/ } \\
\text { Resident, Medical Officer/ House Officer }\end{array}$ \\
\hline Qualification of anesthetist & Categorical & Sub-specialist, Fellow, Consultant, Registrar/Resident, Medical Officer/ House Officer \\
\hline \multicolumn{3}{|l|}{ Process variable } \\
\hline Preoperative CT performed & Binary & Yes, No \\
\hline $\begin{array}{l}\text { Preoperative packed red blood } \\
\text { cells }\end{array}$ & Categorical & None, less that 4 units, more than four units \\
\hline Operation date & Date & \\
\hline Date of admission & Date & \\
\hline Time of admission & Time & \\
\hline Operation commencement time & Time & \\
\hline Operation completion time & Time & \\
\hline Operative procedure performed & Categorical & Non-therapeutic, Foregut, Hepatobiliary, Intestinal, Vascular, Abdominal wall, Genitourinary, Other \\
\hline Approach & Categorical & Laparoscopic, Laparoscopic converted-to-open, Open \\
\hline Wound classification & Categorical & Clean, clean-contaminated, contaminated, dirty \\
\hline Resection performed & Categorical & No, hand sewn, stapled \\
\hline Stoma performed & Categorical & No, involving small bowel, involving large bowel \\
\hline
\end{tabular}


Table 2. Clavien-Dindo Adverse Event Classification System.

\begin{tabular}{|l|l|}
\hline Grade & Definition \\
\hline $\mathbf{1}$ & $\begin{array}{l}\text { Any deviation of the clinical course without the need for pharmacological treatment or surgical, } \\
\text { radiological or endoscopic interventions. }\end{array}$ \\
\hline II & Requiring pharmacological treatment other than such allowed for Grade 1 complications. \\
\hline III a & Requiring surgical, endoscopic or radiological intervention \\
\hline III b & Intervention not under general anaesthesia \\
\hline IV & Intervention under general anaesthesia \\
\hline IV a & $\begin{array}{l}\text { Life-threatening complication (including CNS complications)* } \\
\text { requiring ICU management }\end{array}$ \\
\hline IV b & Single organ dysfunction (including dialysis) \\
\hline V & Multiorgan dysfunction \\
\hline
\end{tabular}

All AE were recorded daily on ward rounds until discharge. All hospitals in the district reported monthly morbidity and mortality at a combined meeting where the outcome measures were further verified.

\section{Analysis}

Risk factors were reclassified as binary predictors to encourage the development of parsimonious models. Only those predictors that had a univariate association $\mathrm{p}>0.1$ were included in the multivariate analysis. Any predictor that was statistically associated with a major $\mathrm{AE}$ was then entered into a stepwise forward entry logistic regression algorithm. The significance level for entry into the final multivariate model was $\mathrm{p}=0.05$. Missing variables were entered into the model as missing. Including presence or absence of a major $\mathrm{AE}$ as a predictor, the above steps were repeated to build models for the secondary outcome measures. All analyses were performed using STATA/ SE version 14.0 (Statacorp LP, College Station, TX, USA). The University of Cape Town approved research ethics for the study.

\section{Results}

450 exploratory laparotomies from the four participating hospitals were included, 319 (70.9\%) were non-trauma procedures and 131 (29.1\%) trauma procedures. The mean age of the non-trauma cohort was 37.9 years (range 13 - 93 years) and the most common diagnoses were acute appendicitis $(152,33.9 \%)$, perforated peptic ulcer $(27,6.0 \%)$, adhesive intestinal obstruction $(23,5.1 \%)$, incarcerated or strangulated hernia ( 22 cases, $4.8 \%)$ and a complication secondary to an abdominal malignancy $(13,2.8 \%)$. The mean age of the trauma cohort was 31.6 years (range $14-60$ years). A penetrating mechanism of injury was reported in 115 (89.9\%) of trauma cases and 60 (45.8\%) were secondary to gunshot injuries. Additional descriptive statistics and outcome measures by hospital are presented in Table 3. In total, there were 71 major AE including 29 deaths representing an overall unadjusted rate of AE of $15.7 \%$ (95\% CI $12.6-19.4$ ) and mortality rate of $6.4 \%$ (95\% CI $4.5-9.1)$. GSH had the highest unadjusted rates of major $\mathrm{AE}(27.9 \%$; 95\% CI 22.1-34.6), LOS $>30$ (7.8\%; 95\% CI 4.7-12.5), ICU admission (24.3\%; 95\% CI 17.1-33.4) and unplanned reoperation (16.1\%; $95 \%$ CI 11.5-21.9).

Factors associated with a major AE are presented in Table 4. Of the 29 predictors in the dataset, $19(65.5 \%)$ had a univariate association with a major complication $(\mathrm{p}<0.1)$. Of these, GSH had a significantly higher proportion of patients older than 55, with an ASA class greater than or equal to 3 , diabetes, a diagnosis of trauma, having received greater than 4 units of blood preoperatively, with a preoperative CT scan, having undergone an open procedure, requiring a resection or a stoma procedure $(\mathrm{p}<0.05)$. No variable had more than $3 \%$ of values missing.
Table 3. Adverse Events after Emergency Laparotomy stratified by hospital in Cape Town, South Africa.

\begin{tabular}{|c|c|c|c|c|c|}
\hline & GSH $^{\wedge}$ & NSH+ & MPH\# & VWH* & Total \\
\hline Hospital level & Central & Regional & District & District & N/A \\
\hline $\begin{array}{l}\text { Procedure } \\
\text { total N (\%) }\end{array}$ & $193(42.8)$ & $115(25.5)$ & $79(17.5)$ & $63(14.0)$ & 450 \\
\hline Mean (range) & $39.4(13-93)$ & $32.4(13-72)$ & $33.6(13-78)$ & $35.2(13-76)$ & $36.1(13-93)$ \\
\hline Male N (\%) & $128(66.6)$ & $68(59.1)$ & $53(67.0)$ & $47(74.6)$ & $296(65.9)$ \\
\hline Trauma N (\%) & $84(43.5)$ & $15(13.0)$ & $23(29.1)$ & $9(14.2)$ & $131(29.1)$ \\
\hline \multicolumn{6}{|c|}{ Outcome measures } \\
\hline $\begin{array}{l}\text { Major Adverse } \\
\text { Event }\end{array}$ & 54 (27.9) & $9(7.8)$ & $5(6.3)$ & $3(4.2)$ & $71(15.7)$ \\
\hline LOS $>30$ & $15(7.7)$ & $1(0.8)$ & $1(1.2)$ & $0(0)$ & $17(3.7)$ \\
\hline ICU admission & $47(24.3)$ & $11(9.5)$ & $1(1.2)$ & $5(7.9)$ & $64(14.2)$ \\
\hline $\begin{array}{l}\text { Unplanned } \\
\text { reoperation }\end{array}$ & $31(16.0)$ & $6(5.2)$ & $2(2.5)$ & $4(6.3)$ & $43(9.5)$ \\
\hline
\end{tabular}

$\mathrm{GSH}^{\wedge}$ Groote Schuur Hospital, NSH+ New Somerset Hospital, MPH\# Mitchell’s Plain Hospital, VWH*

Victoria War Memorial Hospital.

The results of the multivariate regression are presented in Table 5. Age, ASA class, resection status, procedure and preoperative CT status were associated with a major $\mathrm{AE}(\mathrm{p}<0.05)$. Factors associated with $\mathrm{LOS}>30$ were major $\mathrm{AE}$ and resection status. Factors associated with ICU admission included major AE, age, ASA class and resection status. Major AE was the only risk factor associated with unplanned reoperation in the multivariate analysis.

\section{Discussion}

In this study the peri-operative mortality rate was $6.4 \%(95 \%$ CI 4.5 - 9.1) and major AE was $15.7 \%$ (95\% CI 12.6 - 19.4). Factors associated with a major $\mathrm{AE}$, defined as a Clavien Dindo greater than three, included age, $\mathrm{ASA}>3$, bowel resection, preoperative $\mathrm{CT}$, and a non-therapeutic laparotomy. A major AE was associated with all three outcome proxies for increased resource utilisation.

Age and ASA are both well-validated predictors of death and major adverse events $[8,14-16]$. Bowel resection has been shown to be associated with increased risk of death following emergency laparotomy in a study conducted in an international cohort [12]. In our study, pre-operative CT scan and non-therapeutic laparotomy were also associated with the major $\mathrm{AE}$, which has not been previously reported in the literature. Access to a CT scanner is limited in our setting, with the central referral hospital having much better access than the regional and district hospitals. Data from the prehospital setting is not available so if patients were referred to GSH for a CT scan and then operated on at GSH, the prehospital delay associated with the referral for a CT scan could in part explain this association. Moreover, pre-operative CT scan 
Table 4. Univariate association with a major adverse event after emergency laparotomy.

\begin{tabular}{|c|c|c|c|c|}
\hline Risk factor & $\begin{array}{l}\text { Frequency } \\
\text { N (\%) }\end{array}$ & $\begin{array}{l}\text { Missing } \\
\text { N (\%) }\end{array}$ & $\begin{array}{l}\text { OR for major AE } \\
\text { in total cohort } \\
(95 \% \text { CI })\end{array}$ & P-value \\
\hline \multicolumn{5}{|l|}{ Patient variable } \\
\hline Age $\geq 55$ & $204(46.05)$ & $1(0.22)$ & $4.71(2.62-8.66)$ & $<0.0001$ \\
\hline White race & $31(6.89)$ & $\begin{array}{l}4(0.88) \\
1.03\end{array}$ & $(0.38-2.78)$ & NS \\
\hline Male sex & $296(65.92)$ & $1(0.22)$ & $1.18(0.68-2.04)$ & NS \\
\hline $\mathrm{ASA} \geq 3$ & $51(15.94)$ & $7(1.56)$ & $11.07(5.42-22.61)$ & $<0.0001$ \\
\hline $\begin{array}{l}\text { Charlson's comorbidity index } \\
>2\end{array}$ & $13(4.06)$ & $0(0)$ & $1.53(1.25-1.86)$ & $<0.0001$ \\
\hline $\begin{array}{l}\text { Dependency status } \geq \text { partially } \\
\text { dependent }\end{array}$ & $46(14.38)$ & $2(0.44)$ & $1.66(0.74-3.73)$ & NS \\
\hline HIV positive & $39(8.67)$ & $5(1.11)$ & $1.42(0.92-3.34)$ & NS \\
\hline Diabetic & $22(4.89)$ & $3(0.67)$ & $3.31(1.33-8.23)$ & 0.01 \\
\hline Current smoker & $181(40.22)$ & $13(2.89)$ & $1.1(0.67-1.85)$ & NS \\
\hline BMI & $163(36.22)$ & $0(0)$ & $1.79(0.78-4.17)$ & NS \\
\hline GCS $<12$ on arrival & $12(2.67)$ & $0(0)$ & $8.18(2.52-26.57)$ & $<0.0001$ \\
\hline Hypotensive on arrival & $115(25.56)$ & $1(0.22)$ & $4.2(1.37-12.91)$ & $<0.01$ \\
\hline Airway compromised & $9(0.02)$ & $0(0)$ & $9.62(2.23-41.56)$ & $<0.001$ \\
\hline \multicolumn{5}{|l|}{ Problem variable } \\
\hline Diagnosis of trauma & $131(29.11)$ & $0(0)$ & $1.62(0.96-2.76)$ & $<0.1$ \\
\hline Firearm injury & $60(13.33)$ & $3(0.67)$ & $2.73(1.46-5.08)$ & $<0.01$ \\
\hline \multicolumn{5}{|l|}{ Provider variable } \\
\hline VWH* & $63(14.0)$ & $0(0)$ & \multicolumn{2}{|l|}{ Reference } \\
\hline $\mathrm{GSH}^{\wedge}$ & $193(42.89)$ & $0(0)$ & $7.77(2.34-25.83)$ & 0.001 \\
\hline $\mathrm{NSH}+$ & $115(25.6)$ & $0(0)$ & $1.69(0.44-6.51)$ & NS \\
\hline MPH\# & $79(17.56)$ & $0(0)$ & $1.35(0.31-5.89)$ & NS \\
\hline $\begin{array}{l}\text { Surgical trainee most senior } \\
\text { provider }\end{array}$ & $293(65.11)$ & $9(2.0)$ & $0.39(0.24-0.66)$ & $<0.0001$ \\
\hline $\begin{array}{l}\text { Anesthetic trainee most senior } \\
\text { provider }\end{array}$ & $402(89.33)$ & $11(2.44)$ & $0.45(0.23-0.91)$ & $<0.0001$ \\
\hline \multicolumn{5}{|l|}{ Process variable } \\
\hline Preoperative $\mathrm{CT}$ required & $84(18.79)$ & $3(0.67)$ & $3.19(1.83-5.59)$ & $<0.0001$ \\
\hline $\begin{array}{l}\text { Perioperative transfusion }>4 \\
\text { units }\end{array}$ & $39(8.67)$ & $10(2.22)$ & $7.72(3.76-15.82)$ & $<0.0001$ \\
\hline Theatre delay $>6 \mathrm{hrs}$ & $208(46.74)$ & $5(1.11)$ & $1.06(0.64-1.76)$ & NS \\
\hline Open approach & $369(82.0)$ & $0(0)$ & $18.73(2.56-136.91)$ & $<0.01$ \\
\hline Non-therapeutic & $33(7.33)$ & $2(0.44)$ & $2.15(0.95-4.84)$ & $<0.01$ \\
\hline $\begin{array}{l}\text { Wound classification } \\
\geq \text { Contaminated }\end{array}$ & $73(46.20)$ & $5(1.11)$ & $1.88(1.09-3.26)$ & $<0.01$ \\
\hline Any resection performed & 85 (18.89) & $9(2.0)$ & $3.98(2.29-6.91)$ & $<0.0001$ \\
\hline Any stoma performed & $40(8.89)$ & $7(1.56)$ & $2.92(1.43-5.99)$ & $<0.0001$ \\
\hline
\end{tabular}

VWH* Victoria War Memorial Hospital, GSH^^ Groote Schuur Hospital, NSH+ New Somerset Hospital,

MPH\# Mitchell's Plain Hospital.

is reserved for cases with complex pathology or diagnostic uncertainty. There are currently no formal protocols that guide the decision making process of when to image and no information on the time it takes to get the scan. In our study, CT scan may have been associated with a major $\mathrm{AE}$ because it is a proxy for a complicated surgical condition or delay to theatre.

Of the 21 patients with a non-therapeutic laparotomy, the most common diagnoses were 8 cases of abdominal TB (38.1\%), followed by 4 cases of acute pancreatitis (19.1\%), and 3 cases of mesenteric ischaemia (14.3\%). Patients with abdominal tuberculosis and acute pancreatitis who were inadvertently operated on could have explained their higher risk for major $\mathrm{AE}$ [17-19]. In the cases of mesenteric ischaemia without a therapeutic procedure, it is reasonable to believe that the ischaemia was too advanced for any operative intervention and these patients were likely to be palliated. Future studies on the examining the outcomes of non-therapeutic laparotomy are warranted
Table 5. Associations with major adverse events, length of stay, ICU admission and unplanned reoperation following an emergency laparotomy in the Cape Metro West health district.

\begin{tabular}{|c|c|c|c|c|}
\hline Outcome measure & Risk factor & Odds ratio & P-value & $95 \% \mathrm{CI}$ \\
\hline \multicolumn{5}{|l|}{ Major adverse event } \\
\hline & Age $\geq 55$ & 4.14 & 0.001 & $1.78-9.62$ \\
\hline & $\mathrm{ASA} \geq 3$ & 4.11 & 0.001 & $1.79-9.45$ \\
\hline & $\begin{array}{l}\text { Any resection } \\
\text { performed }\end{array}$ & 4.03 & 0.001 & $1.72-9.45$ \\
\hline & $\begin{array}{l}\text { Non-therapeutic } \\
\text { laparotomy }\end{array}$ & 8.57 & 0.001 & $2.51-29.33$ \\
\hline & $\begin{array}{l}\text { Preoperative } \mathrm{CT} \\
\text { required }\end{array}$ & 2.91 & 0.014 & $1.24-6.79$ \\
\hline \multicolumn{5}{|l|}{$\mathrm{LOS}>\mathbf{3 0}$} \\
\hline & $\begin{array}{l}\text { Any resection } \\
\text { performed }\end{array}$ & 10.68 & 0.042 & $1.1-104.06$ \\
\hline & $\begin{array}{l}\text { Occurrence of a } \\
\text { major adverse event }\end{array}$ & 17.63 & 0.013 & $1.82-170.37$ \\
\hline \multirow[t]{4}{*}{ ICU admission } & Age $\geq 55$ & 2.89 & 0.022 & $1.16-7.22$ \\
\hline & $\mathrm{ASA} \geq 3$ & 4.03 & 0.003 & $1.61-10.11$ \\
\hline & $\begin{array}{l}\text { Any resection } \\
\text { performed }\end{array}$ & 2.86 & 0.027 & $1.13-7.25$ \\
\hline & $\begin{array}{l}\text { Occurrence of a } \\
\text { major adverse event }\end{array}$ & 9.84 & $<0.0001$ & $3.98-24.33$ \\
\hline Unplanned reoperation & $\begin{array}{l}\text { Occurrence of a } \\
\text { major adverse event }\end{array}$ & 8.11 & $<0.0001$ & $3.36-19.53$ \\
\hline
\end{tabular}

in our collaborative. Major AE was an independent risk factor for all secondary outcome measures. This association suggests auditing $\mathrm{AE}$ alone may be sufficient and the additional burden of auditing these secondary outcome measures may not be necessary.

Unadjusted postoperative mortality rates (POMR) vary greatly between hospitals and on its own, offers little as a meaningful indicator of surgical quality. GSH had a significantly higher POMR than the other three hospitals but in the risk-adjusted multivariate analysis, GSH was not an independent predictor of death. Comparisons based on POMR have been restricted by the absence of standardized approaches to when it is measured and the ideal denominator. The utility of POMR as an outcomes measure is further limited by it's low event rate and low statistical power $[20,21]$. In this study we have chosen to study major AE as defined as a Clavien Dindo classification of three or more. Initiated in 1992 and updated 5 years ago, the classification system was developed to address the lack of consensus on how to grade postoperative events using a simple, reproducible and flexible system that is applicable irrespective of cultural background. A five year evaluation published in Annals of Surgery, provided strong evidence that the classification system is valid and applicable worldwide in many fields of surgery [13]. In our experience, we found the classification very useful to minimize the subjectivity associated with classifying adverse outcomes as either major or minor. It is based on the therapy needed to correct the $\mathrm{AE}$ and therefore it is not surprising that a primary outcome of ClavienDindo greater than three was associated with all outcomes of increased resource allocation. We believe this is a useful outcome measure to audit in a resource limited context.

For ACS-NSQIP, hospitals collect data only on a sample of patients undergoing any general or vascular surgical procedure under general or regional anesthesia. Our study support the recommendations made by Birkmeyer et al. [1] and recommend that a quality improvement program should rather include data collection on all patients undergoing a specified procedure within each specialty; 'Specialty-level outcomes measures are not sufficiently granular for targeting specific procedures or subspecialty areas for improvement. They may even be 
falsely reassuring and result in missed opportunities for improvement. For example, a hospital's poor performance in colorectal surgery may be masked by better than average outcomes in trauma surgery, or vice versa [1]'. Because a primary interest of these programs is to reduce morbidity and mortality, procedures should be selected, in part, according to their contribution to the overall number of major adverse events within each specialty. A procedure-targeted approach accounts for both the relative frequency and risk associated with each procedure. For some specialties, the large majority of AE occur in a small set of procedures and adopting a targeted approach also limits the number variables required for adequate risk adjustment. Procedure- specific performance measures would also better engage surgeons in their areas of interest or specialization [1]. In LMIC's efforts need to be focused on receiving the greatest return on investment of time and resources. For this reason, highrisk or high-volume procedures must be prioritized for audit and this study supports the suggestion made by Lancet Commission on Global Surgery to target the Bellwether procedures [9].

This study has certain limitations. Only in hospital mortality and adverse events were captured, 30 day follow-up in our setting was not feasible. Reliably assessing the prehospital delay was also not possible as many patients were referred directly from home and establishing when the initial onset of symptoms began became very subjective.

Only the delay from hospital admission to theatre could be reliably assessed. Outcomes were clinician reported and may have been prone to misclassification bias. This was minimized by verifying outcomes at the combined morbidity and mortality meetings.

This study also had several strengths. Data collection can often be time consuming and expensive. Using RedCap as our data collection tool allowed busy clinicians to collect real time data and no dedicated data entry personnel were used. All variables in the dataset were less than $3 \%$ missing. The multi-center nature of the study improved the power and applicability of the results. Further studies using similar methodology to identify factors associated with mortality and adverse events within South Africa or in other LMIC may identify a consistent set of variables. This would contribute towards the development of contextually relevant, coefficient-based, risk prediction models such as those that provide the framework for programs like the ACS-NSQIP and TQIP. Such models could be used preoperatively to enhance the informed consent process as well as guide resource allocation such as postoperative ICU planning. Postoperatively these models could be used to help identify opportunities for quality improvement and monitor the impact of any corrective strategy implemented by comparing observed outcomes to the expected predictions.

In conclusion, this study supports the use of the Clavien Dindo classification system for the comparative outcome assessment of a high volume or high risk procedure as a proxy for measuring the quality of care provided in a surgical collaborative. Such an exercise can identify opportunities for quality improvement and in our experience, has highlighted the need to review the availability and indications for preoperative CT scanning and to continue to audit the rates and circumstances of non-therapeutic laparotomies performed in Cape Town, South Africa.

\section{Acknowledgements}

Our sincere thanks to Dr Kathryn Chu for her critical review of the manuscript and to Dr. Heather Bougard for her support during this study.

\section{References}

1. Birkmeyer JD, Shahian DM, Dimick JB, Finlayson SR, Flum DR, et al. (2008) Blueprint for a new American College of Surgeons: National Surgical Quality Improvement Program. J Am CollSurg207: 777-782. [Crossref]

2. Donabedian A (2005) Evaluating the quality of medical care. 1966. Milbank $Q 83$ 691-729. [Crossref]

3. Birkmeyer JD, Dimick JB, Birkmeyer NJ (2004) Measuring the quality of surgical care: structure, process, or outcomes? J Am CollSurg 198: 626-632. [Crossref]

4. Khuri SF, Henderson WG, Daley J, Jonasson O, Jones RS, et al. (2008) Successful implementation of the Department of Veterans Affairs' National Surgical Quality Improvement Program in the private sector: the Patient Safety in Surgery study. Ann Surg 248: 329-336. [Crossref]

5. Farmer DL (2012) NSQIP lite: a potential tool for global comparative effectiveness evaluations. Arch Surg 147: 803-804. [Crossref]

6. Hall BL, Hamilton BH, Richards K, Bilimoria KY, Cohen ME, et al. (2009) Does surgical quality improve in the American College of Surgeons National Surgical Quality Improvement Program: an evaluation of all participating hospitals. Ann Surg 250: 363-376. [Crossref]

7. Cohen ME, Liu Y, Ko CY, Hall BL (2016) Improved Surgical Outcomes for ACS NSQIP Hospitals Over Time: Evaluation of Hospital Cohorts With up to 8 Years of Participation. Ann Surg 263: 267-273. [Crossref]

8. Anderson JE, Rose J, Noorbakhsh A, Talamini MA, Finlayson SR, et al. (2014) An efficient risk adjustment model to predict inpatient adverse events after surgery. World J Surg 38: 1954-1960. [Crossref]

9. Meara JG, Leather AJ, Hagander L, Alkire BC, Alonso N, et al. (2015) Global Surgery 2030: evidence and solutions for achieving health, welfare, and economic development. Lancet 386: 569-624. [Crossref]

10. Nicol A, Knowlton LM, Schuurman N, Matzopoulos R, Zargaran E, et al. (2014) Trauma Surveillance in Cape Town, South Africa: An Analysis of 9236 Consecutive Trauma Center Admissions. JAMA Surg 149: 549-556. [Crossref]

11. Project REDCap. 2015; Available at: http://www.project-redcap.org/. Accessed June, 24, 2015.

12. Bhangu A, Fitzgerald JE, Fergusson S, Khatri C, Holmer H, et al. (2014) Determining universal processes related to best outcome in emergency abdominal surgery: a multicentre, international, prospective cohort study. BMJ Open 4: e006239. [Crossref]

13. Clavien PA, Barkun J, de Oliveira ML, Vauthey JN, Dindo D, et al. (2009) The ClavienDindo classification of surgical complications: five-year experience. Ann Surg 250: 187-196. [Crossref]

14. Davenport DL, Bowe EA, Henderson WG, Khuri SF, Mentzer RM Jr. (2006) National Surgical Quality Improvement Program (NSQIP) risk factors can be used to validate American Society of Anesthesiologists Physical Status Classification (ASA PS) levels. Ann Surg 243:636- 641. [Crossref]

15. Haynes SR, Lawler PG (1995) An assessment of the consistency of ASA physical status classification allocation. Anaesthesia 50: 195-199. [Crossref]

16. Schluter PJ (2011) The Trauma and Injury Severity Score (TRISS) revised. Injury 42 90-96. [Crossref]

17. Guo Q, Li A, Xia Q, Lu H, Ke N, et al. (2014) Timing of intervention in necrotizing pancreatitis. J GastrointestSurg 18: 1770-1776. [Crossref]

18. van Grinsven J, van Brunschot S, Bakker OJ, Bollen TL, Boermeester MA, et al. (2016) Diagnostic strategy and timing of intervention in infected necrotizing pancreatitis: an international expert survey and case vignette study. HPB (Oxford) 18: 49-56. [Crossref]

19. Islam J, Clarke DL, Thomson SR (2014) Lessons from emergency laparotomy for abdominal tuberculosis in the HIV/AIDS era. S Afr J Surg 52: 10-12. [Crossref]

20. Ng-Kamstra JS, Greenberg SL, Kotagal M, Palmqvist CL, Lai FY, et al. (2015) Use and definitions of perioperative mortality rates in low-income and middle-income countries: a systematic review. Lancet 385 Suppl 2: S29. [Crossref]

21. Palmqvist CL, Ariyaratnam R, Watters DA, Laing GL, Stupart D, et al. (2015) Monitoring and evaluating surgical care: defining perioperative mortality rate and standardising data collection. Lancet 385 Suppl 2: S27. [Crossref]

Copyright: (C2016 Spence RT. This is an open-access article distributed under the terms of the Creative Commons Attribution License, which permits unrestricted use, distribution, and reproduction in any medium, provided the original author and source are credited. 